\title{
The Persistent Challenge of Developing Addiction Pharmacotherapies
}

\author{
Sarah E. Swinford-Jackson, ${ }^{1}$ Charles P. O'Brien, ${ }^{2}$ Paul J. Kenny, ${ }^{3}$ Louk J.M.J. Vanderschuren, ${ }^{4}$ \\ Ellen M. Unterwald, ${ }^{5}$ and R. Christopher Pierce ${ }^{1}$ \\ ${ }^{1}$ Department of Psychiatry, Brain Health Institute, Rutgers University, Piscataway, New Jersey 08854, USA \\ ${ }^{2}$ Department of Psychiatry, Perelman School of Medicine, University of Pennsylvania, Philadelphia, \\ Pennsylvania 19104, USA \\ ${ }^{3}$ Department of Neuroscience, Icahn School of Medicine at Mount Sinai, New York, New York 10029, USA \\ ${ }^{4}$ Department of Animals in Science and Society, Division of Behavioural Neuroscience, Faculty of Veterinary \\ Medicine, Utrecht University, 3584 CM, Utrecht, The Netherlands \\ ${ }^{5}$ Center for Substance Abuse Research and Department of Pharmacology, Lewis Katz School of Medicine, \\ Temple University, Philadelphia, Pennsylvania 19140, USA \\ Correspondence: chris.pierce@rutgers.edu
}

\begin{abstract}
There are currently effective Food and Drug Administration (FDA)-approved therapies for alcohol, nicotine, and opioid use disorders. This article will review the development of eight compounds used in the treatment of drug addiction with an emphasis on pharmacological mechanisms and the utility of preclinical animal models of addiction in therapeutic development. In contrast to these successes, animal research has identified a number of promising medications for the treatment of psychostimulant use disorder, none of which have proven to be clinically effective. A specific example of an apparently promising pharmacotherapeutic for cocaine that failed clinically will be examined to determine whether this truly represents a challenge to the predictive validity of current models of cocaine addiction. In addition, the development of promising cocaine use disorder therapeutics derived from animal research will be reviewed, with some discussion regarding how preclinical studies might be modified to better inform clinical outcomes.
\end{abstract}

$T^{\text {hes }}$ here are currently effective U.S. Food and Drug Administration (FDA)-approved therapies for alcohol, nicotine, and opioid use disorders. ${ }^{6}$ In some cases, these therapeutics were rationally designed and tested using a combination of various animal models of addiction. In many cases, however, effective drug therapies for substance use disorders were derived from the testing of compounds developed for other central nervous system (CNS) disorders (e.g., analgesics and antidepressants), which were tested clinically in the absence of prior animal research using addiction models. This article will review the development of eight compounds that are

\footnotetext{
${ }^{6}$ This is an update to a previous article published in Cold Spring Harbor Perspectives in Medicine [Pierce et al. (2012). Cold Spring Harb Perspect Med 2: a12880. doi: 10.1101/cshperspect.a012880].

Editors: R. Christopher Pierce, Ellen M. Unterwald, and Paul J. Kenny

Additional Perspectives on Addiction available at www.perspectivesinmedicine.org

Copyright (C) 2021 Cold Spring Harbor Laboratory Press; all rights reserved; doi: 10.1101/cshperspect.a040311

Cite this article as Cold Spring Harb Perspect Med 2021;11:a040311
} 
S.E. Swinford-Jackson et al.

currently most effective in the treatment of alcohol, opioid, and nicotine use disorders with an emphasis on pharmacological mechanisms as well as the utility of animal models of addiction in the development of these therapeutics. In contrast to these successes, animal research has identified a number of promising medications for the treatment of psychostimulant use disorders, none of which have proven to be effective clinically. This raises questions about the validity of current animal models of psychostimulant addiction. A specific example of an apparently promising pharmacotherapeutic for cocaine use disorder (the D1 dopamine receptor antagonist ecopipam) that failed clinically will be examined to determine whether this truly represents a challenge to the predictive validity of current models of cocaine addiction. In addition, the development of promising cocaine use disorder therapeutics derived from animal research will be reviewed.

\section{BUPRENORPHINE AND METHADONE FOR OPIOID USE DISORDER}

The earliest references to animal models of addiction in the literature all referred to work on opioids, mainly morphine. Research using animal models prior to 1960 used the term addiction loosely given that the drug of abuse was experimenter delivered. For example, Plant and Pierce (1928) administered very high doses of morphine to dogs daily for 2-3 months. Indeed, the doses chosen were toxic in some cases as the authors reported that "two of our animals died in convulsions on doses of 190 and $220 \mathrm{mg}$ per kg" (Plant and Pierce 1928). At that time, the severity of the withdrawal syndrome was thought to be the primary factor contributing to relapse among opioid-dependent humans. Therefore, Plant and Pierce sought to examine and characterize opioid withdrawal in animals. Following cessation of morphine treatment, they noted that "five of our dogs showed marked changes in temperament during the first week of withdrawal, in that they became very cross" and "one animal died in convulsions on the third day of withdrawal" (Plant and Pierce 1928). These authors summed up their observations as fol- lows: "The period of addiction in dogs has given a picture that follows closely the description of addiction in man [including vomiting, constipation, hypersensitiveness, scratching, irritability, and decrease in narcotic action of the drug]." Note that Pierce and Plant defined addiction as opioid withdrawal and tolerance (Plant and Pierce 1928).

The first valid animal model of addiction was developed in the early 1960s. As a first step toward developing a model in which animals self-administer drugs of abuse, two waterdeprived rhesus monkeys were trained to press a lever to receive intravenous infusions of saline (Clark et al. 1961). The authors also showed that saline self-administration could be extinguished and brought under stimulus control (i.e., the monkeys would lever press for light cues previously paired with the saline infusions) (Clark et al. 1961). Subsequently, it was demonstrated that rats (Weeks 1962) and monkeys (Thompson and Schuster 1964) would self-administer morphine intravenously.

Although results from the self-administration paradigm have contributed significantly to the development of more recent addiction pharmacotherapies, the first successes came from drugs that were developed for other purposes. For example, methadone, the first truly successful substance use disorder therapeutic, was originally developed at Hoechst in the 1930s as an analgesic. Methadone was tested for analgesic efficacy by scientists at Eli Lilly and Company and Burroughs Wellcome \& Company in the 1940s (Scott and Chen 1947; Thorp et al. 1947). In early papers, methadone was sometimes spelled methadon and also was called dolophine. As an aside, it has been erroneously reported that methadone, which was developed in Germany, was originally named after Adolf Hitler (i.e., adolophine). Then, as now, a major goal of opioid research was to identify effective analgesics that lacked an addiction liability. Therefore, methadone was tested by a group of prominent behavioral pharmacologists whose findings were summed up as follows: "we believe that unless the manufacture and use of methadon are controlled addiction to it will become a serious public health problem" (Isbell et al. 
1947). This conclusion was based in part on reports from their recovering opioid-dependent patients such as: “That is great stuff. I wouldn't have believed it possible for a synthetic drug to be so like morphine. Can you get it outside? Will it be put under the narcotic laws? I wish I could get it to kick my next habit." The authors also noted that "methadon prevented the appearance of signs of physical dependence in 12 men who had been proved to be addicted to morphine" (Isbell et al. 1947). These observations suggested that methadone might be used to treat opioid use disorder. This idea was not tested until the 1960s, with the publication of the landmark study by Dole and Nyswander (1965), which demonstrated that methadone relieved "narcotic hunger" and produced tolerance such that the euphoric effect of heroin was substantially blunted (Dole and Nyswander 1965).

Although methadone and morphine are both full $\mu$-opioid receptor agonists with substantial addiction liabilities, methadone is a preferable opioid use disorder therapeutic because of a substantially longer half-life and higher oral bioavailability. Methadone distribution is restricted to clinics to ensure that the drug is taken orally, which obviates withdrawal and maintains tolerance in the absence of euphoria. Methadone is not prescribed for home use because of the legitimate fear that, in the absence of monitoring, the drug will be solubilized and administered intravenously, thereby producing a high roughly equivalent to morphine or heroin administered by the same route. In the case of methadone, the clinical trial came before animal studies. Over the years, a number of animal studies have confirmed that methadone prevents opioid withdrawal and blunts relapse in animal models of craving (Goode 1971; Jones and Prada 1977; Negus 2006).

Although there is no question that methadone has proven to be effective in the treatment of opioid use disorder, there are several problems with the methadone clinic model. Primarily, the distance to the closest clinic may render daily clinic visits unfeasible. For some patients living in close proximity to a clinic, the stigma associated with daily visits to a methadone clinic reduces compliance. A clever pharmacological strategy was developed to produce a therapeutic for opioid use disorder that could be taken at the convenience of the patient. It was noted that opioid receptor agonists have good oral bioavailability, whereas the opioid receptor antagonist naloxone does not. Thus, if a pill contains both compounds and is taken orally, the opioid receptor agonist effect predominates. In contrast, if the therapeutic is administered intravenously, the antagonist would block the agonist effect. This strategy led to the development of Suboxone, which is a combination of buprenorphine and naloxone. Buprenorphine, which was developed by Reckitt and Colman in the 1970s as an analgesic, was chosen over methadone because it is a partial $\mu$-opioid receptor agonist, which, in contrast to methadone, has a low instance of death associated with overdose (Mendelson and Jones 2003). Suboxone was approved by the FDA for the treatment of opioid use disorder in 2002 following the passage of DATA 2000 by the U.S. Congress, which allowed individual physicians to be certified to prescribe opioidbased therapeutics for the treatment of opioid use disorder. Although Suboxone rapidly became the first-line prescription treatment for opioid use disorder (Department of Veterans Affairs and Department of Defense 2015), limits on the number of opioid-dependent patients each physician is allowed to treat have constrained the even wider use of this effective medication. Accessible and effective pharmacotherapeutic treatments for opioid use disorder, like Suboxone, are particularly important given the emergence of the opioid epidemic, declared a public health emergency by the U.S. Department of Health and Human Services in 2017.

\section{NALTREXONE FOR OPIOID USE DISORDER AND ALCOHOL USE DISORDER}

In the early 1970s, receptor-binding assays were used to show that "narcotic antagonists" such as naloxone bind to specific receptors in the brain. Opioid receptor antagonists including naltrexone and naloxone were subsequently tested as pharmacotherapies for opioid addiction (Martin et al. 1973). The discovery of endogenous opioids and their receptors prompted research 
S.E. Swinford-Jackson et al.

into the potential role of opioid peptides in the effects of many drugs including alcohol. Initial reports suggested that naltrexone and naloxone reduced alcohol preference in hamsters and rats (Ross et al. 1976) and attenuated alcohol reinforcement in rhesus monkeys (Altshuler et al. 1980). Based on these and similar findings, a placebo-controlled, double-blind clinical trial examining the effect of naltrexone on alcohol relapse was performed. Results indicated that naloxone cut the relapse rate approximately in half compared to controls (Volpicelli et al. 1992). These results were rapidly replicated, with the highest rates of abstinence observed in patients who received both naltrexone and supportive therapy (O'Malley et al. 1992). Numerous trials subsequently showed that naltrexone is effective in the treatment of alcohol use disorder.

A single-nucleotide polymorphism at A118G (Asn40Asp) in exon I of the $\mu$-opioid receptor was identified and shown to triple the potency of $\beta$-endorphin at these receptors (Bond et al. 1998). This polymorphism was shown to be associated with alcohol addiction (Bart et al. 2005) and individuals with one or two copies of the Asp40 allele treated with naltrexone had significantly lower rates of relapse than patients homozygous for the Asn40 allele (Oslin et al. 2006). Thus, naltrexone treatment of alcohol use disorder is one of the few examples of a pharmacogenomic therapeutic. Naltrexone, which is marketed as ReVia and Depade, has been used in the treatment of opioid use disorder since 1984 and alcohol use disorder since 1995. In 2006, an extended-release injectable formulation of naltrexone (Vivitrol) was approved by the U.S. FDA for the treatment of alcohol and opioid use disorders. Naltrexone and acamprosate are each currently first-line pharmacotherapies for alcohol use disorder in the United States.

\section{ACAMPROSATE FOR ALCOHOL USE DISORDER}

Acamprosate, a homotaurine derivative, was developed in France in the 1980s. The rationale was that since alcohol activates $\mathrm{GABA}_{\mathrm{A}}$ receptors and homotaurine is a GABA receptor agonist, perhaps homotaurine derivatives might serve as alcohol replacement therapies (Boismare et al. 1984). Indeed, calcium bis acetylhomotaurine (acamprosate) significantly reduced the voluntary intake of alcohol by rats (Boismare et al. 1984). Based on this result, acamprosate was tested in a double-blind placebo-controlled clinical trial with the success criterion defined as alcohol abstinence following 3 months of outpatient treatment. Results indicated that 20 of 33 patients receiving acamprosate remained alcohol-free compared to 12 of 37 subjects receiving placebo (Lhuintre et al. 1985). The efficacy of acamprosate as an effective therapeutic for alcohol use disorder has been repeatedly replicated (Mason and Heyser 2010). Acamprosate has been used for the treatment of alcohol use disorder in Europe since 1989. Surprisingly, the precise mechanism of action of acamprosate remains unclear. Because of the ambiguity of the drug's mechanism of action, the U.S. FDA delayed approval of acamprosate (marketed as Campral) until 2004.

Although acamprosate was targeted for the treatment of alcohol use disorder because of presumed effects on GABA and taurine transmission, the therapeutic effects of this drug appear to be due primarily to effects on glutamate systems. Although initial reports suggested that acamprosate is an NMDA receptor antagonist, subsequent work indicated that acamprosate acts as a partial agonist at spermidine sites on NMDA receptors (Dahchour and De Witte 2000) and also is an mGluR5 receptor antagonist (De Witte et al. 2005). Alcohol withdrawal is associated with a number of changes in neurotransmission including, notably, increased glutamate transmission in regions of the CNS (Mason and Heyser 2010). A growing body of evidence is consistent with the notion that acamprosate blunts alcohol craving and withdrawal by normalizing glutamate transmission (Heilig and Egli 2006).

Disulfiram also is used in the treatment of alcohol use disorder. However, this drug does not specifically target aspects of addiction or withdrawal. Rather, disulfiram blocks aldehyde dehydrogenase resulting in the accumulation of 
acetaladehyde after alcohol ingestion, which produces an array of aversive symptoms. Thus, disulfiram acts as a punishing agent in the event of relapse rather than a therapeutic. Although disulfiram continues to be used in the treatment of alcohol use disorder, there are concerns related both to the safety and effectiveness of this compound (Heilig and Egli 2006).

\section{NICOTINE, VARENICLINE, AND BUPROPION FOR NICOTINE USE DISORDER}

The history of nicotine replacement therapies dates to a letter Dr. Claes Lundgren, a physiology professor at Lund University, sent to his friend Ove Fernö at Aktiebolaget Leo pharmaceutical company in 1967. Lundgren and his colleague, Stephan Lichtneckert, suggested oral nicotine as a substitute for tobacco based on the observation that sailors sometimes switched from smoking to chewing tobacco without difficultly when assigned to submarine duty. Fernö immediately recognized the promise and commercial potential of nicotine replacement and embarked on a research program to design a means to orally administer nicotine with delayed absorption. The result was nicotine gum. Years later, Fernö reflected on his work as follows: "Putting nicotine into chewing gum is not an invention. Fixing the nicotine to an ion exchange resin and putting that into a chewing gum to enable the chewer to control the rate of release-that is an invention" (Ferno 1994). Initial clinical trials performed in Sweden (Ferno et al. 1973) and London (Russell et al. 1976) in the 1970s indicated that nicotine gum was effective in reducing nicotine withdrawal and maintaining smoking abstinence. A landmark randomized doubleblind, placebo-controlled clinical trial published in 1982 indicated that smoking abstinence was $47 \%$ in the nicotine gum group compared to a $21 \%$ success rate among controls (Jarvis et al. 1982). These results led to the approval of nicotine gum, which Aktiebolaget Leo (acquired as McNeil by Johnson \& Johnson) named Nicorette, by the U.S. FDA in 1984. Nicotine gum, nicotine lozenges, patches, nasal sprays, and inhalers are all popular forms of nicotine replacement therapy and are effective in maintaining abstinence from tobacco use (Polosa and Benowitz 2011). The combination of slow-release forms like transdermal patches and acute nicotine replacement via lozenges or gum have been shown to be particularly effective at maintaining abstinence and reducing craving in meta-analyses of clinical trials (Shah et al. 2008; Lindson et al. 2019). Electronic cigarettes (or e-cigarettes) were initially considered as another form of nicotine replacement therapy. However, concerns about lack of consistent regulations, unknown long-term health consequences, and the possibility of their use as a "gateway" to smoking cigarettes or cannabis, particularly among the youth, all contribute to the failure of any e-cigarettes or similar vaping products to be approved by the FDA as nicotine use disorder therapeutics (Sharpless 2019).

Animal studies are notably absent in the history of Nicorette. More recently, a rational strategy led to the development of the partial nicotinic receptor agonist varenicline for smoking cessation. Nicotinic acetylcholine receptors (nAChRs) are pentameric ligand-gated ions channels composed of combinations of at least 17 different subunits (Pierce and Kumaresan 2006). A number of studies indicate that $\alpha 4 \beta 2$ nAChRs, which are the most widely expressed subtypes in the brain, play a critical role in nicotine-induced dopamine release and reinforcement (Mineur and Picciotto 2008). The $\alpha 4 \beta 2$ $\mathrm{nAChR}$ partial agonist varenicline was developed by Pfizer for smoking cessation. The rationale was that varenicline might serve the dual purpose of moderately increasing mesolimbic dopamine levels, which are reduced during nicotine withdrawal, and also blunting nicotine-induced dopamine release in the event of relapse (Coe et al. 2005). Animal studies revealed that varenicline reduced nicotine-induced dopamine release in the nucleus accumbens (Coe et al. 2005) and inhibited nicotine self-administration as well as the reinstatement of nicotine seeking (O'Connor et al. 2010). A randomized double-blind clinical trial demonstrated that the smoking abstinence rate with varenicline was $44 \%$ compared with nearly $18 \%$ for placebo (Gonzales et al. 2006; Jorenby et al. 2006). Notably, measures of nicotine withdrawal and craving also were reduced by 
S.E. Swinford-Jackson et al.

varenicline (Gonzales et al. 2006). Based on these results, the U.S. FDA fast-tracked approval for varenicline (Chantix) as a smoking cessation drug, which was granted in 2006.

The initial varenicline smoking cessation clinical trials used bupropion as a positive control. The abstinence rate for bupropion was nearly $30 \%$, which is significantly greater than placebo but substantially lower than varenicline (Gonzales et al. 2006; Jorenby et al. 2006). Bupropion, which was developed by Burroughs Wellcome \& Company (now GlaxoSmithKline), was approved for the treatment of depression by the U.S. FDA in 1985. A sustained release formulation of bupropion, marketed as Wellbutrin SR, remains a highly successful antidepressant. Antidepressants were tested as smoking cessation agents because cigarette smokers have higher rates of depression that may be exacerbated by nicotine withdrawal (Glassman et al. 1990). Double-blind placebo-controlled clinical trials revealed that a sustained-release formulation of bupropion significantly increased the rate of smoking cessation (Hurt et al. 1997). Bupropion was approved for the treatment of nicotine addiction in 1997 and is marketed as Zyban. Similar to other antidepressants, bupropion is a dopamine and norepinephrine reuptake inhibitor. Interestingly, bupropion also is an $\mathrm{nAChR}$ antagonist at various subtypes including $\alpha 4 \beta 2$ (Slemmer et al. 2000), which may account for the effectiveness of bupropion as a smoking cessation agent relative to other antidepressants.

\section{PSYCHOSTIMULANTS}

Despite decades of focused research efforts, there are no effective pharmacotherapies for psychostimulant use disorders. Indeed, a broad range of drugs targeting multiple CNS transmitter systems have been tested as treatments for psychostimulant dependence without success (Kampman et al. 2005). Drugs that modulate dopaminergic transmission were among the first assessed for the treatment of psychostimulant addiction both in animal studies and clinical trials. Dopamine receptors are classified as either D1-like or D2-like. There was substantial interest in D1-like dopamine receptor antago- nists as psychostimulant use disorders therapeutics as they lack the sometimes serious extrapyramidal side effects associated with D2-like dopamine receptor antagonists (Haney and Spealman 2008). Animal and human laboratory studies revealed that acute administration of D1-like dopamine receptor antagonists attenuated the reinforcing effects of cocaine (Romach et al. 1999; Platt et al. 2002). However, clinical use of a D1-like dopamine receptor antagonist requires repeated administrations. Unfortunately, when humans were maintained on the D1-like dopamine receptor antagonist, ecopipam, cocaine self-administration actually increased (Haney et al. 2001). This finding is consistent with results from rhesus monkeys utilizing continuous drug administration (Kleven and Woolverton 1990) and is likely due to antagonist-induced increases in D1 dopamine receptor density in the brain (Haney and Spealman 2008). It is important to emphasize that in the case of ecopipam, the animal and human data paralleled one another both when the drug was administered acutely and repeatedly.

Fortunately, there are other examples of rationally developed therapeutics for psychostimulant use disorders that appear promising. $\mathrm{N}$-acetylcysteine (NAC), which is used to treat acetaminophen overdose, has been shown to normalize decreased nucleus accumbens glutamate levels following cocaine self-administration as well as the reinstatement of cocaine-seeking behavior in rats (Baker et al. 2002, 2003). Clinical trials demonstrate that NAC attenuated cocaine use and decreased desire to use cocaine (LaRowe et al. 2007; Mardikian et al. 2007). Recent clinical trials also support the ability of NAC to reduce incentive salience for cocaine cues (Levi et al. 2017) and delay relapse in cocaine-abstinent subjects (LaRowe et al. 2013), suggesting that NAC may be therapeutically beneficial in maintaining abstinence and/or preventing relapse. Another interesting strategy is the development of cocaine vaccines. Active immunization with a cocaine vaccine attenuated cocaine self-administration as well as the reinstatement of cocaine seeking in rats (Kantak et al. 2000). Clinical data indicate that the cocaine vaccine, TA-CD, produced selective anti- 
Developing Addiction Pharmacotherapies

cocaine antibodies, which blunted the intoxicating effects of cocaine (Haney et al. 2010). In these studies, insufficient immune responses to vaccines is a persistent issue, which has led to the development of novel vaccines designed to generate consistently high antibody titers (Wee et al. 2012). An adenovirus-based cocaine vaccine reduced motivation for cocaine and reinstatement of cocaine seeking in rats (Wee et al. 2012) and delayed reacquisition of cocaine self-administration in nonhuman primates (Evans et al. 2016); this cocaine vaccine dAd5GNE is currently under investigation in a phase I clinical trial. An obvious issue with vaccines is their specificity. That is, a cocaine vaccine will not be effective against amphetamine or its derivatives, which might be substituted for cocaine during a bout of drug craving. Cocaine antibodies also could be whelmed with a sufficiently high dose of the drug.

In terms of the validity of animal models of psychostimulant addiction, we note that the preclinical and clinical data are consistent when the animal model is drug self-administration (Haney and Spealman 2008). Moreover, two of the more promising cocaine use disorder therapeutics (NAC and cocaine vaccines) were tested primarily with self-administration models of addiction and relapse.

\section{SUMMARY AND CONCLUSIONS}

We have reviewed the development of the eight main compounds currently used in the treatment of substance use disorders. As outlined in Table 1, two of these drugs are antagonists, one is a transporter inhibitor, two are full agonists, and three are partial agonists. Clearly, the most successful treatments for addiction involve receptor stimulation, with the primary goal of obviating drug withdrawal. Agonist therapeutics also reproduce some of the positive aspects of the drug of abuse (e.g., mood elevation), which enhances compliance. Partial agonists are particularly appealing as they blunt the psychoactive effects of the drug of abuse in the event of relapse. Moreover, the risk of overdose is substantially diminished with partial relative to full agonists.
Table 1 Therapeutics used in the treatment of substance use disorders and their mechanism of action

\begin{tabular}{|c|c|c|}
\hline Therapeutic & $\begin{array}{l}\text { Drug of } \\
\text { abuse }\end{array}$ & $\begin{array}{c}\text { Mechanism of } \\
\text { action }\end{array}$ \\
\hline Acamprosate & Alcohol & Partial agonist \\
\hline Buprenorphine & Opioids & Partial agonist \\
\hline Bupropion & Nicotine & Indirect agonist \\
\hline Methadone & Opioids & Agonist \\
\hline Naloxone & Opioids & Antagonist \\
\hline Naltrexone & $\begin{array}{l}\text { Alcohol, } \\
\text { opioids }\end{array}$ & Antagonist \\
\hline Nicotine & Nicotine & Agonist \\
\hline Varenicline & Nicotine & Partial agonist \\
\hline
\end{tabular}

The fact that partial agonists are particularly effective addiction therapeutics raises the question of partial dopamine agonist treatments for psychostimulant use disorders (Platt et al. 2002; Keck et al. 2015). Surprisingly, there is very little clinical research in this area. Indeed, the only compound tested clinically is the D2-like dopamine receptor partial agonist aripiprazole, which is approved for the treatment of schizophrenia, depression, and bipolar disorder. Aripiprazole reduced cocaine reinstatement in rats (Feltenstein et al. 2007) and decreased the discriminative stimulus properties of amphetamine in a human laboratory study (Lile et al. 2005). Initial clinical trial results have been mixed with one study reporting that aripiprazole reduced cocaine craving and use (Meini et al. 2011). In contrast, another clinical trial showed that aripiprazole increased the self-administration of smoked cocaine, apparently to compensate for decreased subjective effects of cocaine (Haney et al. 2011). These experiments highlight both the promise of partial agonists in the treatment of psychostimulant use disorders and the persistent frustration in developing clearly effective therapeutics for stimulant craving and addiction.

Overall, it is clear that a disconnect exists between even well-designed preclinical studies that identify potential addiction pharmacotherapies and clinical outcomes in patients with substance use disorders. One important factor may be sex differences in the responsiveness to any given treatment. In 2016, the National Institutes 
S.E. Swinford-Jackson et al.

of Health instituted a requirement that all research studies account for sex as a biological variable. Increased preclinical focus on sex may clarify whether the effects of potential pharmacotherapies are dependent on sex, expanding upon previous studies that may have been predominantly performed in males. Personalized medicine strategies could also unlock new treatments for substance use disorders. Pharmacogenomic approaches that tailor treatment to individuals based on single-nucleotide polymorphisms, illustrated above by improved outcomes of naltrexone treatment for alcohol use disorder in patients with the Asp40 allele (Oslin et al. 2006), are excellent examples of how individual differences can be leveraged for better pharmacotherapeutic development and implementation.

\section{REFERENCES}

Altshuler HL, Phillips PE, Feinhandler DA. 1980. Alteration of ethanol self-administration by naltrexone. Life Sci 26: 679-688. doi:10.1016/0024-3205(80)90257-X

Baker DA, Shen H, Kalivas PW. 2002. Cystine/glutamate exchange serves as the source for extracellular glutamate: modifications by repeated cocaine administration. Amino Acids 23: 161-162. doi:10.1007/s00726-001-0122-6

Baker DA, McFarland K, Lake RW, Shen H, Toda S, Kalivas PW. 2003. N-acetyl cysteine-induced blockade of cocaine-induced reinstatement. Ann NY Acad Sci 1003: 349-351. doi:10.1196/annals.1300.023

Bart G, Kreek MJ, Ott J, LaForge KS, Proudnikov D, Pollak L, Heilig M. 2005. Increased attributable risk related to a functional $\mu$-opioid receptor gene polymorphism in association with alcohol dependence in central Sweden. Neuropsychopharmacology 30: 417-422. doi:10.1038/sj .npp.1300598

Boismare F, Daoust M, Moore N, Saligaut C, Lhuintre JP, Chretien P, Durlach J. 1984. A homotaurine derivative reduces the voluntary intake of ethanol by rats: are cerebral GABA receptors involved? Pharmacol Biochem Behav 21: 787-789. doi:10.1016/S0091-3057(84)80020-9

Bond C, LaForge KS, Tian M, Melia D, Zhang S, Borg L, Gong J, Schluger J, Strong JA, Leal SM, et al. 1998. Singlenucleotide polymorphism in the human $\mu$ opioid receptor gene alters $\beta$-endorphin binding and activity: possible implications for opiate addiction. Proc Natl Acad Sci 95: 9608-9613. doi:10.1073/pnas.95.16.9608

Clark R, Schuster CR, Brady JV. 1961. Instrumental conditioning of jugular self-infusion in the rhesus monkey. Science 133: 1829-1830. doi:10.1126/science.133.3467 .1829

Coe JW, Brooks PR, Vetelino MG, Wirtz MC, Arnold EP, Huang J, Sands SB, Davis TI, Lebel LA, Fox CB, et al. 2005 Varenicline: an $\alpha 4 \beta 2$ nicotinic receptor partial agonist for smoking cessation. J Med Chem 48: 3474-3477. doi:10 .1021/jm050069n

Dahchour A, De Witte P. 2000. Ethanol and amino acids in the central nervous system: assessment of the pharmacological actions of acamprosate. Prog Neurobiol 60: $343-$ 362. doi:10.1016/S0301-0082(99)00031-3

Department of Veterans Affairs and Department of Defense. 2015. Clinical practice guideline for the management of substance use disorders version 3. Available at https:// www.healthquality.va.gov/guidelines/MH/sud/VADoDS UDCPGRevised22216.pdf

De Witte P, Littleton J, Parot P, Koob G. 2005. Neuroprotective and abstinence-promoting effects of acamprosate: elucidating the mechanism of action. CNS Drugs 19: $517-$ 537. doi:10.2165/00023210-200519060-00004

Dole VP, Nyswander M. 1965. A medical treatment for diacetylmorphine (heroin) addiction. A clinical trial with methadone hydrochloride. JAMA 193: 646-650. doi:10 .1001/jama.1965.03090080008002

Evans SM, Foltin RW, Hicks MJ, Rosenberg JB, De BP, Janda KD, Kaminsky SM, Crystal RG. 2016. Efficacy of an adenovirus-based anti-cocaine vaccine to reduce cocaine self-administration and reacqusition using a choice procedure in rhesus macaques. Pharmacol Biochem Behav 150-151: 76-86. doi:10.1016/j.pbb.2016.09.008

Feltenstein MW, Altar CA, See RE. 2007. Aripiprazole blocks reinstatement of cocaine seeking in an animal model of relapse. Biol Psychiatry 61: 582-590. doi:10.1016/j.bio psych.2006.04.010

Ferno O. 1994. Conversation with ove ferno. Addiction 89: 1215-1226. doi:10.1111/j.1360-0443.1994.tb03300.x

Ferno O, Lichtneckert SJA, Lundgren CEG. 1973. A substitute for tobacco smoking. Psychopharmacologia 31: 201204. doi:10.1007/BF00422510

Glassman AH, Helzer JE, Covey LS, Cottler LB, Stetner F, Tipp JE, Johnson J. 1990. Smoking, smoking cessation, and major depression. JAMA 264: 1546-1549. doi:10 .1001/jama.1990.03450120058029

Gonzales D, Rennard SI, Nides M, Oncken C, Azoulay S, Billing CB, Watsky EJ, Gong J, Williams KE, Reeves KR, et al. 2006. Varenicline, an $\alpha 4 \beta 2$ nicotinic acetylcholine receptor partial agonist, vs sustained-release bupropion and placebo for smoking cessation: a randomized controlled trial. JAMA 296: 47-55. doi:10.1001/jama.296.1.47

Goode PG. 1971. An implanted reservoir of morphine solution for rapid induction of physical dependence in rats. Br J Pharmacol 41: 558-566. doi:10.1111/j.1476-5381 1971.tb08054.x

Haney M, Spealman R. 2008. Controversies in translational research: drug self-administration. Psychopharmacology (Berl) 199: 403-419. doi:10.1007/s00213-008-1079-x

Haney M, Ward AS, Foltin RW, Fischman MW. 2001. Effects of ecopipam, a selective dopamine D1 antagonist, on smoked cocaine self-administration by humans. Psychopharmacology (Berl) 155: 330-337. doi:10.1007/s00 2130100725

Haney M, Gunderson EW, Jiang H, Collins ED, Foltin RW. 2010. Cocaine-specific antibodies blunt the subjective effects of smoked cocaine in humans. Biol Psychiatry 67: 59-65. doi:10.1016/j.biopsych.2009.08.031 
Haney M, Rubin E, Foltin RW. 2011. Aripiprazole maintenance increases smoked cocaine self-administration in humans. Psychopharmacology (Berl) 216: 379-387. doi:10.1007/s00213-011-2231-6

Heilig M, Egli M. 2006. Pharmacological treatment of alcohol dependence: target symptoms and target mechanisms. Pharmacol Ther 111: 855-876. doi:10.1016/j .pharmthera.2006.02.001

Hurt RD, Sachs DP, Glover ED, Offord KP, Johnston JA Dale LC, Khayrallah MA, Schroeder DR, Glover PN, Sullivan CR, et al. 1997. A comparison of sustained-release bupropion and placebo for smoking cessation. $N$ Engl J Med 337: 1195-1202. doi:10.1056/NEJM199710233 371703

Isbell H, Wikler A, Eddy NB, Wilson JL, Moran CF. 1947. Tolerance and addiction liability of 6-dimethylamino-44-diphenylheptanone-3 (methadon). J Am Med Assoc 135: 888-894. doi:10.1001/jama.1947.02890140008003

Jarvis MJ, Raw M, Russell MA, Feyerabend C. 1982. Randomised controlled trial of nicotine chewing-gum. $\mathrm{Br}$ Med J (Clin Res Ed) 285: 537-540. doi:10.1136/bmj.285 .6341 .537

Jones BE, Prada JA. 1977. Effects of methadone and morphine maintenance on drug-seeking behavior in the dog Psychopharmacology (Berl) 54: 109-112. doi:10.1007/ BF00426764

Jorenby DE, Hays JT, Rigotti NA, Azoulay S, Watsky EJ, Williams KE, Billing CB, Gong J, Reeves KR., Varenicline Phase 3 Study Group. 2006. Efficacy of varenicline, an $\alpha 4 \beta 2$ nicotinic acetylcholine receptor partial agonist, vs placebo or sustained-release bupropion for smoking cessation: a randomized controlled trial. JAMA 296: 56-63. doi:10.1001/jama.296.1.56

Kampman KM, Leiderman D, Holmes T, LoCastro J, Bloch DA, Reid MS, Shoptaw S, Montgomery MA, Winhusen TM, Somoza EC, et al. 2005. Cocaine rapid efficacy screening trials (CREST): lessons learned. Addiction 100: 102-110. doi:10.1111/j.1360-0443.2005.00987.x

Kantak KM, Collins SL, Lipman EG, Bond J, Giovanoni K, Fox BS. 2000. Evaluation of anti-cocaine antibodies and a cocaine vaccine in a rat self-administration model. Psychopharmacology (Berl) 148: 251-262. doi:10.1007/ s002130050049

Keck TM, John WS, Czoty PW, Nader MA, Newman AH 2015. Identifying medication targets for psychostimulant addiction: unraveling the dopamine D3 receptor hypothesis. J Med Chem 58: 5361-5380. doi:10.1021/jm501512b

Kleven MS, Woolverton WL. 1990. Effects of continuous infusions of SCH 23390 on cocaine- or food-maintained behavior in rhesus monkeys. Behav Pharmacol 1: 365373. doi:10.1097/00008877-199000140-00010

LaRowe SD, Myrick H, Hedden S, Mardikian P, Saladin M, McRae A, Brady K, Kalivas PW, Malcolm R. 2007. Is cocaine desire reduced by $\mathrm{N}$-acetylcysteine? Am J Psychiatry 164: 1115-1117. doi:10.1176/ajp.2007.164.7.1115

LaRowe SD, Kalivas PW, Nicholas JS, Randall PK, Mardikian PN, Malcolm RJ. 2013. A double-blind placebo-controlled trial of $\mathrm{N}$-acetylcysteine in the treatment of cocaine dependence. Am J Addict 22: 443-452. doi:10.1111/j .1521-0391.2013.12034.x

Levi Bolin B, Alcorn JL III, Lile JA, Rush CR, Rayapati AO, Hays LR, Stoops WW. 2017. N-acetylcysteine reduces cocaine-cue
Developing Addiction Pharmacotherapies

attentional bias and differentially alters cocaine self-administration based on dosing order. Drug Alcohol Depend 178: 452-460. doi:10.1016/j.drugalcdep.2017.05.039

Lhuintre JP, Daoust M, Moore ND, Chretien P, Saligaut C, Tran G, Bosimare F, Hillmand B. 1985. Ability of calcium bis acetyl homotaurine, a GABA agonist, to prevent relapse in weaned alcoholics. Lancet 325: 1014-1016. doi:10.1016/S0140-6736(85)91615-0

Lile JA, Stoops WW, Vansickel AR, Glaser PE, Hays LR, Rush CR. 2005. Aripiprazole attenuates the discriminative-stimulus and subject-rated effects of Damphetamine in humans. Neuropsychopharmacology 30: 2103-2114. doi:10.1038/sj.npp.1300803

Lindson N, Chepkin SC, Ye W, Fanshawe TR, Bullen C, Hartmann-Boyce J. 2019. Different doses, durations and modes of delivery of nicotine replacement therapy for smoking cessation. Cochrane Database Syst Rev 4: CD013308.

Mardikian PN, LaRowe SD, Hedden S, Kalivas PW, Malcolm RJ. 2007. An open-label trial of $\mathrm{N}$-acetylcysteine for the treatment of cocaine dependence: a pilot study. Prog Neuropsychopharmacol Biol Psychiatry 31: 389-394. doi:10 .1016/j.pnpbp.2006.10.001

Martin WR, Jasinski DR, Mansky PA. 1973. Naltrexone, an antagonist for the treatment of heroin dependence. Effects in man. Arch Gen Psychiatry 28: 784-791. doi:10 $.1001 /$ archpsyc.1973.01750360022003

Mason BJ, Heyser CJ. 2010. Acamprosate: a prototypic neuromodulator in the treatment of alcohol dependence. CNS Neurol Disord Drug Targets 9: 23-32. doi:10.2174/ 187152710790966641

Meini M, Moncini M, Cecconi D, Cellesi V, Biasci L, Simoni G, Ameglio M, Pellegrini M, Forgione RN, Rucci P. 2011 Aripiprazole and ropinirole treatment for cocaine dependence: evidence from a pilot study. Curr Pharm Des 17: 1376-1383. doi:10.2174/138161211796150783

Mendelson J, Jones RT. 2003. Clinical and pharmacological evaluation of buprenorphine and naloxone combinations: why the 4:1 ratio for treatment? Drug Alcohol Depend 70: S29-S37. doi:10.1016/S0376-8716(03)00057-7

Mineur YS, Picciotto MR. 2008. Genetics of nicotinic acetylcholine receptors: relevance to nicotine addiction. Biochem Pharmacol 75: 323-333. doi:10.1016/j.bcp.2007 .06 .010

Negus SS. 2006. Choice between heroin and food in nondependent and heroin-dependent rhesus monkeys: effects of naloxone, buprenorphine, and methadone. J Pharmacol Exp Ther 317: 711-723. doi:10.1124/jpet.105.095380

O'Connor EC, Parker D, Rollema H, Mead AN. 2010. The $\alpha 4 \beta 2$ nicotinic acetylcholine-receptor partial agonist varenicline inhibits both nicotine self-administration following repeated dosing and reinstatement of nicotine seeking in rats. Psychopharmacology (Berl) 208: 365-376. doi:10 .1007/s00213-009-1739-5

O'Malley SS, Jaffe AJ, Chang G, Schottenfeld RS, Meyer RE, Rounsaville B. 1992. Naltrexone and coping skills therapy for alcohol dependence. A controlled study. Arch Gen Psychiatry 49: 881-887. doi:10.1001/archpsyc.1992.01 820110045007

Oslin DW, Berrettini WH, O'Brien CP. 2006. Targeting treatments for alcohol dependence: the pharmacogenetics of naltrexone. Addict Biol 11: 397-403. doi:10.1111/j $.1369-1600.2006 .00036 . x$ 
S.E. Swinford-Jackson et al.

Pierce RC, Kumaresan V. 2006. The mesolimbic dopamine system: the final common pathway for the reinforcing effect of drugs of abuse? Neurosci Biobehav Rev 30: 215-238. doi:10.1016/j.neubiorev.2005.04.016

Plant OH, Pierce IH. 1928. Studies of chronic morphin poisoning in dogs. I: General symptoms and behavior during addiction and withdrawal. J Pharmacol Exp Therapeut 33: 329-357.

Platt DM, Rowlett JK, Spealman RD. 2002. Behavioral effects of cocaine and dopaminergic strategies for preclinical medication development. Psychopharmacology (Berl) 163: 265-282. doi:10.1007/s00213-002-1137-8

Polosa R, Benowitz NL. 2011. Treatment of nicotine addiction: present therapeutic options and pipeline developments. Trends Pharmacol Sci 32: 281-289. doi:10.1016/j .tips.2010.12.008

Romach MK, Glue P, Kampman K, Kaplan HL, Somer GR, Poole S, Clarke L, Coffin V, Cornish J, O'Brien CP, et al. 1999. Attenuation of the euphoric effects of cocaine by the dopamine D1/D5 antagonist ecopipam (SCH 39166). Arch Gen Psychiatry 56: 1101-1106. doi:10.1001/arch psyc.56.12.1101

Ross D, Hartmann RJ, Geller I. 1976. Ethanol preference in the hamster: effects of morphine sulfate and naltrexone, a long-acting morphine antagonist. Proc West Pharmacol Soc 19: 326-330.

Russell MA, Wilson C, Feyerabend C, Cole PV. 1976. Effect of nicotine chewing gum on smoking behaviour and as an aid to cigarette withdrawal. $\mathrm{Br}$ Med J 2: 391-393. doi:10 $.1136 / \mathrm{bmj} .2 .6032 .391$

Scott CC, Chen KK. 1947. Further observations on the pharmacology of dolophine (methadon, Lilly). J Pharmacol Exp Ther 91: 147-156.
Shah SD, Wilken LA, Winkler SR, Lin SJ. 2008. Systematic review and meta-analysis of combination therapy for smoking cessation. J Am Pharm Assoc 48: 659-665. doi:10.1331/JAPhA.2008.07063

Sharpless N. 2019. How the FDA is regulating E-cigarettes FDA voices: perspective from FDA leadership and experts: U.S. Food and Drug Administration. Available at https://www.fda.gov/news-events/fda-voices-perspectivesfda-leadership-and-experts/how-fda-regulating-e-cigarettes

Slemmer JE, Martin BR, Damaj MI. 2000. Bupropion is a nicotinic antagonist. J Pharmacol Exp Ther 295: 321-327.

Thompson T, Schuster CR. 1964. Morphine self-administration, food-reinforced, and avoidance behaviors in rhesus monkeys. Psychopharmacologia 5: 87-94. doi:10.1007/ BF00413045

Thorp RH, Walton E, Ofner P. 1947. Analgesic activity in compounds related to amidone. Nature 159: 679-680. doi:10.1038/159679a0

Volpicelli JR, Alterman AI, Hayashida M, O’Brien CP. 1992. Naltrexone in the treatment of alcohol dependence. Arch Gen Psychiatry 49: 876-880. doi:10.1001/archpsyc.1992 .01820110040006

Wee S, Hicks MJ, De BP, Rosenberg JB, Moreno AY, Kaminsky SM, Janda KD, Crystal RG, Koob GF. 2012. Novel cocaine vaccine linked to a disrupted adenovirus gene transfer vector blocks cocaine psychostimulant and reinforcing effects. Neuropsychopharmacology 37: 10831091. doi:10.1038/npp.2011.200

Weeks JR. 1962. Experimental morphine addiction: method for automatic intravenous injections in unrestrained rats. Science 138: 143-144. doi:10.1126/science .138 .3537 .143 


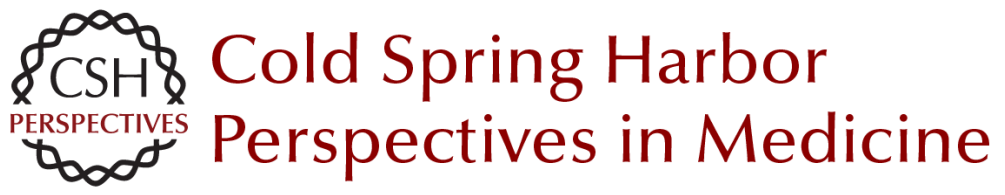

\section{The Persistent Challenge of Developing Addiction Pharmacotherapies}

Sarah E. Swinford-Jackson, Charles P. O'Brien, Paul J. Kenny, Louk J.M.J. Vanderschuren, Ellen M. Unterwald and R. Christopher Pierce

Cold Spring Harb Perspect Med 2021; doi: 10.1101/cshperspect.a040311 originally published online June 29, 2020

\section{Subject Collection Addiction}

Developments from Bulk Optogenetics to

Single-Cell Strategies to Dissect the Neural

Circuits that Underlie Aberrant Motivational States

Jose Rodriguez-Romaguera, Vijay M.K.

Namboodiri, Marcus L. Basiri, et al.

Consequences of Parental Opioid Exposure on

Neurophysiology, Behavior, and Health in the

Next Generations

Fair M. Vassoler and Mathieu E. Wimmer

Animal Models of the Behavioral Symptoms of

Substance Use Disorders

Louk J.M.J. Vanderschuren and Serge H. Ahmed

Translational Research in Nicotine Addiction

Miranda L. Fisher, James R. Pauly, Brett Froeliger, et al.

Neonatal Opioid Withdrawal Syndrome (NOWS): A

Transgenerational Echo of the Opioid Crisis Andrew E. Weller, Richard C. Crist, Benjamin C. Reiner, et al.

Impairment of Synaptic Plasticity by Cannabis, $\Delta^{\mathbf{9}}$ -THC, and Synthetic Cannabinoids

Alexander F. Hoffman, Eun-Kyung Hwang and Carl R. Lupica

Drug-Evoked Synaptic Plasticity of Excitatory

Transmission in the Ventral Tegmental Area Camilla Bellone, Michael Loureiro and Christian Lüscher

Opioid-Induced Molecular and Cellular Plasticity

of Ventral Tegmental Area Dopamine Neurons

Marie A. Doyle and Michelle S. Mazei-Robison
The Persistent Challenge of Developing Addiction

Pharmacotherapies

Sarah E. Swinford-Jackson, Charles P. O'Brien,

Paul J. Kenny, et al.

Opioid Modulation of the Gut-Brain Axis in Opioid-Associated Comorbidities

Li Zhang and Sabita Roy

Epigenetics of Drug Addiction

Andrew F. Stewart, Sasha L. Fulton and lan Maze

Genetic Vulnerability to Opioid Addiction

Brian Reed and Mary Jeanne Kreek

Glutamatergic Systems and Memory Mechanisms

Underlying Opioid Addiction

Jasper A. Heinsbroek, Taco J. De Vries and Jamie Peters

Mechanisms of Nicotine Addiction

Marina R. Picciotto and Paul J. Kenny

Neural Substrates and Circuits of Drug Addiction Matthew W. Feltenstein, Ronald E. See and Rita A. Fuchs

The Role of the Central Amygdala in Alcohol

Dependence Marisa Roberto, Dean Kirson and Sophia Khom

For additional articles in this collection, see http://perspectivesinmedicine.cshlp.org/cgi/collection/ 